\title{
Support of Industry 4.0 in Research Framing Documents and Trio Program
}

\author{
Marek JETMAR
}

AMBIS, Prague, Czech Republic

marek.jetmareambis.cz

\begin{abstract}
The article deals with the way in which the declared support of Industry 4.0 was reflected in the conceptual documents in the area of research, development and innovations of the Czech Republic - National Policy on Research, Development and Innovation for the years 2016-2020 and National Research and Development Strategy for Smart Specialization of the Czech Republic (background document for implementation European structural and investments funds). A key tool for its support is the Trio Program of the Ministry of Industry and Trade, which was created as a result of the implementation of the S3 strategy in the Czech Republic.

Due to the start of the program implementation in 2016, valid knowledge about outputs and results is not yet available, but it is possible to obtain the first information from financial and factual control of projects. The article identifies the main findings resulting from the factual and financial control of projects launched in August of this year.
\end{abstract}

Keywords: Industry 4.0, Research, Development and Innovation, Program Trio

\section{$1 \quad$ Industry 4.0 as a part of research and innovation policy of the Czech Republic}

\subsection{Framing documents}

The Industry 4.0 issue has received great attention in public space, the debate has been going on since the beginning of decade. In the end, it became part of government policy in the Czech Republic, after the basic theses and objectives were approved by the Government Resolution No. 729/2016 to Initiative Industry 4.0.[6]. However, the objectives and priorities of this policy are also reflected in conceptual documents on applied research, development, industrial research, etc. The key government documents are an updated National Policy on Research, Development and Innovation for the years 2016-2020, approved by Government Resolution no. 135/2016 [3] and the so-called National Research and Innovation Strategy for Smart Specialization of the Czech Republic, actualization by Government Resolution no. 634/2016.

The purpose of the National Research and Development Strategy for Smart Specialization of the Czech Republic [7, 8], hereinafter referred to as the "National S3 
Strategy", is the effective targeting of European, national, regional and private) - to activities aimed at strengthening research and innovation capacity in the priority outlined prospective areas, key for the development of the national economy.

The final version of the National Research and Innovation Strategy for Smart Specialization of the Czech Republic was in the form of an update containing a fundamental change in the concept and focus of the design part approved by the Government of the Czech Republic on 11 July 2016. On 29 September 2016, a representative of the European Commission a letter announcing the approval of the update of the National S3 Strategy for the Czech Republic.

\subsection{Smart specialization in the European context}

Smart Specialization Strategy (S3 strategy) is a concept for growth based on Smartness, Sustainability and Inclusivity. In view of the European roofing, it is closely linked to the objectives of the EUROPE 2020 A European strategy for smart, sustainable and inclusive growth EUROPEAN COMMISSION 2020 (Communication from the Commission (2010) 2020, in short, Europe 2020) [1], in particular to those parts of it which are linked to investment in education, research, development and innovations.

Europe 2020 is a ten-year EU strategy that focuses on job creation and economic growth. It was launched in 2010 to create the conditions for smart and sustainable growth promoting social inclusion. The primary purpose of the S3 strategy is to promote economic growth and transformation towards a knowledge-based economy, taking into account the societal challenges and conditions of Member States and their regions.

The existence of the S3 strategy is also a prerequisite for the implementation of European Union regional policy interventions (European Structural and Investment Funds, ESIF) in the field of research, development and innovation support. According to the so-called General Regulation (Regulation (EC) No 1303/2013 of the European Parliament and of the Council) [2], it is incumbent on the Commission to prepare and submit to the European Commission a smart specialization strategy for those Member States or regions wishing to invest ESIF funds in the following thematic objectives:

- Strengthening research, technological development and innovation,

- Improving access to information and communication technologies (ICT), use and quality of ICT.

Failure to meet the ex ante condition would mean blocking the so-called interim payments by the European Commission and, in essence, avoiding the use of ESIF resources for that purpose in a given country or region.

A specific but key feature of the S3 strategy design and implementation is the emphasis on the so-called "entrepreneurial discovery process" (EDP), which in addition to public administration includes the participation of entrepreneurs, researchers and other socio-economic groups, including civil society as an innovation user (so-called quadruple helix). This process applies not only to defining the objectives of the strategy but must take place throughout the implementation of the 
strategy in order to provide both feedback and verification of implemented interventions as well as new ideas and recommendations for targeting prepared interventions and profiling proposed areas of specialization to which the interventions will be directed.

\subsection{Czech approach}

In the Czech Republic, S3 has been fulfilled by a specific approach. At national level, a National S3 has been set up, which defines objectives and priorities, and specifies national domains of specialization. At regional level (NUTS 3), 14 regional S3 strategies were created, which were subsequently declared as S3 annexes. They represent an autonomous view of regional actors on intelligent specialization in their territories. Their preparation was parallel to the creation of a national document. The Ministry of education, youth and sport, at that time responsible for the preparation of the S3 strategy (or fulfillment of the preconditions), has in fact made it possible to create regional documents within the separate competence of the regions.

The issue of Industry 4.0 is reflected in the priority Advanced machinery/technology for strong and globally competitive industry (automotive and other vehicle producers) and immediately in the priority Digital market technologies and electrical engineering, in section Electronics and electrical engineering in the digital era. "Industry 4.0 generates new requirements for servomotors, actuators and similar drives; manufacturing technologies require specific motors, often as embedded solutions." [5]

It is also emphasized the link to Electrical Engineering, the field of sensors (advanced sensors, actuators, data aggregators, new system parts and components, embedded systems, fibre-optic technologies and sensors and methods for the processing of sensor data) as well as the field of automation, robotics, mechatronics, measurement and simplified application of industrial automation and robotisation to new industrial processes, especially to human-robot/machine collaboration and virtual and augmented reality (development of glasses). Industry 4.0 also inherently includes industrial process automation, diagnostic systems, control and information systems, systems controlling technological processes, industrial transfer arms or equipment for intelligent transport systems.

\section{$2 \quad$ Implementation of Industry 4.0 concept}

\subsection{Research and development programs of the Ministry of Industry and Trade}

The adoption of these basic governmental concepts has not only had an impact on the focus of the objectives of the Operational Programs Research, Development and Education and Enterprise and Competitiveness for Innovation but has also been reflected in the new structure and objectives of national $\mathrm{R} \& \mathrm{D}$ programs. The result 
was also the adoption of the Trio program in 2015 and the preparation of the followup Trend program in 2018/19-22.

The Ministry of Industry and Trade has prepared a new program to support research and development, called TRIO, which was approved by Government Resolution dated May 25, 2015 no. 379 [4]. TRIO program is implemented through public tenders in research, experimental development and innovation in accordance to Law no. 130 / 2002 Coll., on support for research, experimental development and innovation [9].

TRIO program runs from $2016-2021$ and the total amount of support in this period amount to 3700 millions CZK. The first public tender (Call) was opened in the second half of 2015 and for 2016 is to support the approved projects allocated a total of 300 mil. CZK. In autumn 2016 was stated the second public tender with some 710 mil. CZK and in spring 2017, the third Call, with total amount 1070 mil. CZK

The program focuses on the development of potential of the Czech Republic in the field of key enabling technologies (KETs) such as photonics, micro and nanoelectronics, nanotechnology, industrial biotechnology, advanced materials and advanced manufacturing technologies. It closely follows the topics accentuated by Industry 4.0 .

Only projects that reasonably expect at least one result of $\mathrm{R} \& \mathrm{D}$ from the following types of results (categorization according to Information System for Research, Experimental Development and Innovation).

- F - utility or industrial design,

- $\mathrm{G}$ - prototype, functional sample,

- P - patent,

- $\mathrm{R}$ - software,

- Z - pilot operation, proven technology.

In particular, the program will contribute to strengthening the competitiveness of the Czech economy by moving it to the knowledge-based economy.

The public funds are granted to support the development of new product features and increasing the efficiency, security, sustainability and reliability of processes (including energy and material cost reduction), utilizing new KETs knowledge. An integral part of these objectives is also the decline of the energy intensity of the economy, the efficient use of resources and the implementation of technological changes leading to the reduction of the use of materials with high production energy demands. Specific benefits of the Program include:

- increasing the innovative performance of the supported enterprises,

- strategic orientation of R \& D in areas with the highest potential and benefits for the economy,

- increasing the applicability of research results in KETs,

- increase in R \& D expenditure,

- developing effective cooperation between the business and research sectors,

- incorporating emerging top research centers and other capacities supported from public funds into the innovation system. 


\subsection{Program conditions and their fulfillment}

The fundamental rights and obligations of the provider and the beneficiaries are framed in the wording of the Program, respectively in individual public tenders (the Call) and reflect the provisions of Act No. 130/2002 Coll., On the Promotion of Research, Experimental Development and Innovation from Public Funds and on Amendments to Related Acts.

Applicants for project support under Act No. 130/2002 Coll. are enterprises - legal entities and natural persons who are engaged in economic activities and which deal with the project in effective cooperation with at least one research organization. The applicant may also be a body with the status of a research organization, but must act as an enterprise in the proposed project, i.e. demonstrate the ability to co-finance the project solution from non-public sources, demonstrate the implementation of the results in practice and act as an enterprise. In this case, the project may not be solved in the effective cooperation of several entities.

Other participants in the project can be enterprises and research organizations legal entities that meet the definition of a research organization by law, the Commission Regulation and the Framework. The assessment of whether it fulfills the definition of a research organization will be performed by the provider on a case-bycase basis for each entity when assessing the design of the project, in accordance with appraisal process of the Government Council for Research, Development and Innovation.

As a result of the adoption of the Trio program, it was necessary to revitalize the management and control mechanisms at the Ministry of Industry and Trade (MIT), which were suppressed after the completion of the TIP program and the activation of the programs of the Czech Technology Agency.

In connection with the implementation of this program, control mechanisms and rules of factual and financial control were set up. There are also the first findings from past inspections.

\subsection{The first finding of support}

In the first and second public tenders, about 200 projects were supported. Interest of applicants exceeds the earmarked allocation. As the projects are implemented only for a few months, the information about the realization is detectable from the outputs of the control.

The factual control of TRIO projects began at the end of 08/2017. The state of fulfillment of the material content of the projects from the beginning of their solution until the time of the inspection was verified. Appropriate written documentation was evaluated and physical check on site was carried out at the beneficiary, including expert interview with the researcher, the specific procedure and the results of the solution including the outputs were evaluated. In cases where another project participant participated in the project, the way of its cooperation with the beneficiary (expert report on material fulfillment) was assessed. In most cases, minutes of check- 
ins or internal meetings were submitted to fulfill the content of the project with other participants in the project.

Until 1 December 2017 (22 projects audited), no medium / high risk was incurred in the implementation of the phases. What is concerning the outcomes, the completion dates are usually planned until the end of the project and cannot be assessed yet.

Other Findings - Substantive factual and administrative:

- non-acceptance of the text of Annex P-2 (staging, outcomes) of the contract with the Ministry of Industry and Trade in the documents of the beneficiary, in particular the factual content of the annual report, changes of the planned phase terms without the consent of the Ministry of Industry and Trade -6 findings,

- not entering new contracts with other participants or incomplete updating of contracts with other participants from the time the application was processed - 4 cases,

- incompleteness or confusion of information in annual reports, non-compliance with the formal model in Annex P-3 of the MIT contract -20 findings,

- insufficient level of assessment in the opponent's report, total or partial noncompliance with the design of the MIT - 7 findings,

- the procedure for fulfillment of other obligations arising from the contract with the Ministry of Industry and Trade - 11cases.

The file being studied is still very small. Yet everything is obviously the accumulation of errors - on average two to three shortcomings. The most frequent offence is the lack of details in the annual report.

Control authority asked in all detected cases of deficiencies in the recipients'documents to remove deficiencies and make replenishments within the specific deadline. Recipients are currently meeting deadlines. In the case of factual control, the finding is not from the point of view of error so crucial. The course of work corresponds to the solvers' obligations stated in the project application and treaty. The difference may be during the stages and the formalization of their real and planned course. Planned results of individual stages are usually achieved.

What is concerning financial control, the list of irregularities is larger. Typical problems are quality of internal control document for the start of project and financial management (absence, insufficient set-up and resource usage rules), misallocation of funds from the grant account, detention of resources, poor financial relations with other stakeholders, using of subsidy to pay VAT even though beneficiary is a VAT payer etc. 20 projects have been checked so far. There is summarization of findings:

- The internal control document was not in accordance with the terms of the Agreement -10 cases,

- The contract for participation in the project solution did not contain conditions similar to those stipulated in the Contract - 9 findings,

- Exclusion of costs covered from non-public sources that were excluded as ineligible (the funding ratio was respected and there was no breach of budgetary discipline) - 3 cases, 
- Badly executed payments from a separate bank account corrected by the recipient during the calendar year (no budgetary discipline has been violated) - 6 findings,

- The bank account was not a separate current account (suspicion of breach of budgetary discipline) - 3 cases,

- Incorrect data in Financial Settlement -7 cases,

- Deferred allowance (suspicion of breach of budgetary discipline) - 6 findings.

The deficiency with the greatest impact on project implementation is a misconception of the obligations contained in the beneficiary's contract with MIT in the agreement with another participant. This, in a situation of insufficient coercion of the beneficiary, may not only result in the return of the subsidy misused by another participant but also in the negative financial impact on the beneficiary.

These mistakes and shortcomings are often repeated and subject to control findings. In the event of a breach of budgetary discipline, an internal control body initiates an appeal to the tax office, which will decide on the amount of the levy and the penalty.

\section{Conclusions}

The basic policy framework for Industry 4.0 support has been adopted in the Czech Republic. It has also succeeded in linking it with basic government documents in the area of research, development and innovation. A special national program has also been created to highlight issues related to Industry 4.0. Factual results will be evident in the coming months.

Despite the fact that so far there are no more significant outputs of the Program Trio, as a result of the fact that these are usually multiannual research projects, whose implementation started not earlier than in the second half of 2016, it is possible to draw on at least the findings of factual and financial control.

Factual information will be included in the annual reports submitted to the Trio Council, which are the subject of the opposition of external experts. Progress on project implementation will make it possible to evaluate the achievement of the Trio Program's objectives and the national S3 strategy in 2018.

\section{References}

1. European Commission: Communication from the Commission EUROPE 2020 A strategy for smart, sustainable and inclusive growth Commission of the European Union: Europe 2020 A European strategy for smart, sustainable and inclusive growth (COM (2010) 2020).

2. European Parliament and the Council: Regulation (EU) No 1303/2013 of 17 December 2013 laying down common provisions on the European Regional Development Fund, the European Social Fund, the Cohesion Fund, the European Agricultural Fund for Rural Development and the European Maritime and Fisheries Fund and laying down general provisions on the European Regional Development Fund, the European Social Fund, the Cohesion Fund and the European Maritime and Fisheries Fund and repealing Council 
Regulation (EC) No 1083/2006. Official Journal of the European Union. L 347, 20.12.2013, p. 320-469

3. Government of the Czech Republic: Government Resolution no. 135/2016 to National Policy on Research, Development and Innovation for the years 2016-2020.

4. Government of the Czech Republic: Government Resolution no. 379/2015 to Trio Program.

5. Government of the Czech Republic: Government Resolution no. 634/2016 to Actualization of National Research and Innovation Strategy for Smart Specialization of the Czech Republic.

6. Government of the Czech Republic: Government Resolution No. 729/2016 to Initiative Industry 4.0.

7. Ministry of Education, Youth and Sports of the Czech Republic: National Research and Development Strategy for Smart Specialization of the Czech Republic 2014 http://www.vyzkum.cz/FrontClanek.aspx idsekce $=753765 \& \mathrm{ad}=1 \&$ attid $=761392, \quad$ last accessed 2017/12/06.

8. Ministry of Education, Youth and Sports of the Czech Republic: National Research and Development Strategy for Smart Specialization of the Czech Republic 2016. http://www.vyzkum.cz/FrontClanek.aspx idsekce=753765\&ad=1\&attid=804523, last accessed 2017/12/06.

9. Parliament of the Czech Republic: Act No. 130/2002 Coll., On the Promotion of Research, Experimental Development and Innovation from Public Funds and on Amendments to Related Acts. 